\title{
Asthma: audit of peak flow rate guidelines for admission and discharge
}

\author{
M R H Taylor
}

\begin{abstract}
A two part 8.5 month study was undertaken to see if peak expiratory flow rate (PEFR) could be used to guide casualty officers deciding whether to admit or discharge children with asthma. In part 1 PEFR, immediate treatment, and admission or discharge of all children attending because of asthma were recorded. In part 2 the same information was recorded after the introduction of admission and discharge guidelines based on PEFR.

After the introduction of guidelines the proportion of children admitted with a PEFR $\geqslant 40 \%$ expected after casualty treatment fell from $43 \%$ to $26 \%$ (part $144 / 101$, part $238 / 145)$. For a PEFR $>60 \%$ the rate fell from $23 \%$ to $5 \%$ (part $112 / 52$, part 2 4/80). There was no significant change in the reattendance rate.

PEFR can help to reduce unnecessary admissions, provided appropriate normal values and guidelines are supplied.

(Arch Dis Child 1994; 70: 432-434)
\end{abstract}

The peak flow meter provides a convenient means of measuring air flow in children. The peak expiratory flow rate (PEFR) should provide a useful guide for casualty officers in deciding whether or not to admit a patient. However, the correlation between pulmonary function tests and hospital admission is poor. ${ }^{1}$ Most charts of children's normal PEFR values are based on height which is not usually measured in casualty departments. Perhaps for these two reasons the peak flow meter tends to be underused in casualty. ${ }^{2}$ Normal values for PEFR based on age are available, ${ }^{4}$ which would overcome the latter difficulty. A two part study was performed, firstly to assess the admission rate in relation to PEFR and secondly, on the basis of the information obtained, to see if the PEFR could be of value to the casualty officer in deciding on admission or discharge.

Department of Paediatrics (Trinity College Dublin), National Children's Hospital, Harcourt Street, Dublin 2, Ireland

Correspondence to: Dr Taylor.

Accepted 1 December 1993
$20 \%$ of the 50 th centile (figs 1 and 2 ) in keeping with the guidelines (see 'study design').

PEFR

Two Mini-Wright low range peak flow meters were used to measure PEFR. The meters were checked weekly throughout the study using a pneumotachygraph (Vitalograph Compact) calibrated by a 1 litre syringe which was in turn calibrated by water displacement. No drift was detected in the meters. Peak flow rates were measured before nebuliser treatment in the casualty department and 10 minutes after a bronchodilator had been given via a Hudson nebuliser powered by oxygen. In the analysis of results PEFR was expressed as '\% expected' (that is PEFR after nebuliser treatment $\times 100 /$ expected PEFR for age). The expected PEFR was taken as the 50th centile for age to the nearest six months. As the lower age limit for the normal values was 5 years only children of 4.75 years and over were included for analysis of PEFR.

\section{STUDY DESIGN}

Over an 8.5 month period all children attending the casualty department because of asthma were studied. The diagnosis of asthma was made by the casualty officer on the basis of the history, clinical findings, and response to treatment or had been made at a previous outpatient consultation or inpatient stay.

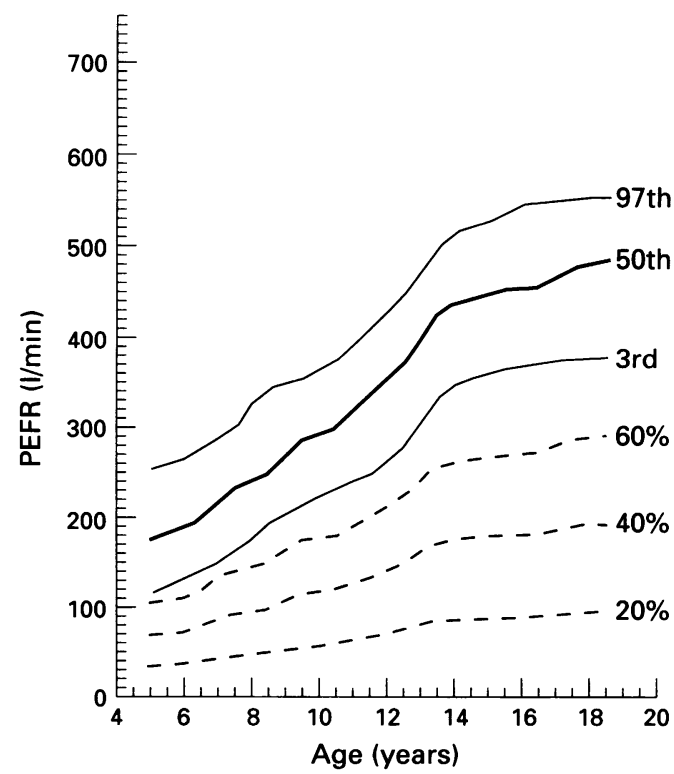

Figure 1 Showing normal PEFR values for age in girls as supplied for part 2 of the study.

\section{Patients and methods} PEFR CHARTS

Charts of PEFR against age were prepared for girls and boys from the smoothed data of Carson, Hoey, and Taylor. ${ }^{4}$ The 97th, 50th, and 3 rd centiles were shown and also $50 \%$ and $25 \%$ of the 50 th centile value. These charts were installed in the casualty department and forms provided for recording patient details. For part 2 of the study the $50 \%$ and $25 \%$ lines were removed and replaced by $60 \%, 40 \%$, and 


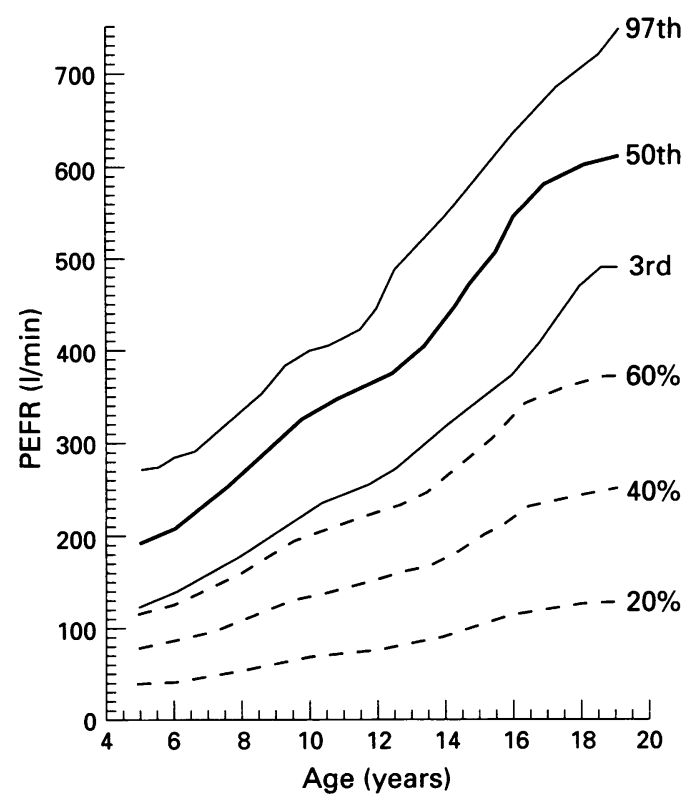

Figure 2 Showing normal PEFR values for age in boys as supplied for part 2 of the study.

Part 1 of the study was observational. Part 2 followed part 1 without an interval. At the end of part 1 the results were examined and guidelines drawn up to assist in the management of patients. The guidelines were as follows:

Guidelines for the admission and discharge of children with asthma based on PEFR readings AFTER SALBUTAMOL BY NEBULISER PEFR

Above $60 \%$ of expected - admission probably unnecessary

$40 \%$ to $60 \%$ of expected - consider admission Less than $40 \%$ of expected - admission probably necessary

BEFORE SALBUTAMOL BY NEBULISER THESE VALUES ARE ABOUT $20 \%$ OF EXPECTED LOWER

'\% Of expected' is the percentage of the 50 th centile for the child's age. The $20 \%, 40 \%$, and $60 \%$ values are given on the graphs.

\section{Remember}

(1) The child's mother usually knows more about how her child's asthma behaves than anyone else, heed what she says.

(2) Make sure that the parents have adequate medication for the child and can give it.

(3) Consider the use of a short course of prednisolone for children being discharged.

(4) The effect of a dose of nebulised salbutamol will only last about three hours.
The findings of the part 1 study, these guidelines and the charts shown in figs 1 and 2 were presented to the casualty officers and part 2 of the study started. The $\chi^{2}$ test was used for statistical analysis.

\section{Results}

One hundred and thirty nine attendances in part 1 and 188 in part 2 were of children $4 \cdot 75$ years or older, of whom 131 and 176 respectively had complete data for analysis. After nebuliser treatment 93\% (286/308) of attenders could register a value of $30 \mathrm{l} / \mathrm{min}$ (the lowest point on the scale) or above.

Sixteen children reattended within 48 hours for the same asthmatic episode. Six reattended in part 1 and one was discharged. Ten reattended in part 2 and four were discharged. The reattendance rates in parts 1 and 2 were not significantly different $(p=0.856$, $\chi^{2}=0.033, \mathrm{df}=1$ ).

In part 1 of the study there was a very large overlap in PEFR between those admitted and those discharged. On the basis of these results the guidelines were prepared and the charts of normal values revised to show ' $40 \%$ and $60 \%$ of expected' lines (figs 1 and 2). Part 2 of the study then started.

A summary of the results is presented in the table. There was a considerable reduction in the proportion admitted in the PEFR $\geqslant 40 \%$ expected group $\left(p=0.0069, \chi^{2}=8.071, d f=1\right.$; difference in percentages $17 \%, 95 \%$ confidence interval (CI) $5 \%$ to $29 \%$ ). A similar change occurred in the children with a PEFR $>60 \%$ expected $\left(p=0.0046, \chi^{2}=9 \cdot 668, d f=1\right.$; difference in percentages $18 \%, 95 \%$ CI $6 \%$ to $30 \%$ ). The fall in admissions in the $40 \%$ to $60 \%$ group did not reach statistical significance. There was no significant change in the proportion of children admitted with a PEFR less than $40 \%$ expected.

\section{Discussion}

In 1985 Carson and Taylor reported a reattendance rate of $24 \%$ (22/93) from this casualty department. ${ }^{2}$ This is in keeping with the $19 \%(15 / 79)$ representation rate reported by Le Souef et al..$^{5}$ The present reattendance rate of $5 \%(16 / 327)$ is probably due to increased use of oral steroid treatment in the acute attack rather than reliance on nebulised salbutamol alone.

It was suggested that patients discharged under this scheme might have reattended elsewhere rather than represented to the same hospital. In order to study this 56 consecutive patients discharged from casualty were followed up by telephone one week after

Number of children admitted and discharged in each peak flow group in parts 1 and 2

\begin{tabular}{|c|c|c|c|c|c|c|c|c|}
\hline \multirow{2}{*}{$\begin{array}{l}P E F R \\
\text { (\% expected) }\end{array}$} & \multicolumn{2}{|l|}{ Part 1} & \multicolumn{2}{|l|}{ Part 2} & \multicolumn{2}{|c|}{$\%$ Admitted } & \multirow[b]{2}{*}{$x^{2}$} & \multirow[b]{2}{*}{ p Value } \\
\hline & No admitted & No discharged & No admitted & No discharged & Part 1 & Part 2 & & \\
\hline $0-<40 \%$ & 25 & 5 & 27 & 4 & 83 & 87 & 0.002 & 0.9575 \\
\hline $40 \%-60 \%$ & 32 & 17 & 34 & 31 & 65 & 52 & 1.936 & 0.2301 \\
\hline$>60 \%$ & 12 & 40 & 4 & 76 & 23 & 5 & 8.045 & 0.0046 \\
\hline$\geqslant 40 \%$ & 44 & 57 & 38 & 107 & 43 & 26 & $7 \cdot 309$ & 0.0069 \\
\hline
\end{tabular}


discharge. Sixteen families had no telephone or telephone contact number or could not be contacted after five or more attempts. None of the remaining 40 patients had been admitted to hospital. Seven attended a general practitioner within five days (though all patients had been requested to do so). Three attended only to obtain a prescription, and only one had his treatment changed. One other patient was started on sodium cromoglycate at another hospital's outpatient clinic. It was concluded that the scheme was providing effective care and was not merely transferring patient care to another site.

Worthington and Ahuja found that values for forced expiratory volume in one second given to the clinician after the decision to admit or discharge had been made did not influence it in $97 \%$ of cases. ${ }^{1}$ In the present study knowledge of the PEFR and the normal values but without guidelines for admission and discharge resulted in a large overlap in PEFR values between those admitted and discharged. This changed when guidelines were provided. Throughout both parts of the study emphasis was laid on complete data collection but no comments were made on the decision to admit or discharge. The results of each part of the study were only released on completion of that section. In our hospital the decision to admit or discharge is normally made by the casualty officer (a paediatric senior house officer); very occasionally a paediatric medical registrar is called to decide. No change was made to the casualty officers' training in asthma management during the two parts of the study. As far as can be judged the casualty officers were no more expert or experienced in part 2 than in part 1 .

The casualty officers have welcomed the guidelines and feel that they make it easier to manage children with asthma. Normal values for younger children have been requested. The suggestion that the PEFR level for discharge might be reduced to $50 \%$ of expected was greeted with concern that children needing admission might then be discharged.

In a study of PEFR and self management of asthma in general practice (which included a small number of children) only those with PEFR less than $30 \%$ of the patient's own normal value were regarded as requiring urgent medical treatment, while those with values between $30 \%$ and $50 \%$ started a course of oral steroid. ${ }^{6}$ The knowledge of personal normal values may allow lower action levels than population normal values. The paper's authors, however, felt that these action levels might have been set too low.

The range between 40 and $60 \%$ of expected remains a difficult area. It may be worthwhile attempting to reduce the $60 \%$ to $50 \%$ despite the casualty officers' concern. Alternatively provision of four to five hours' intensive treatment in a casualty or daycare ward followed by reassessment may prove to be the appropriate management for these patients. A casualty ward was not available during the present study.

This study shows that PEFR can play a valuable part in the management of childhood asthma in a casualty department provided appropriate normal values and guidelines are supplied. If this is done the number of unnecessary admissions can be reduced. The likelihood of inappropriate discharge should also be diminished.

The author thanks the medical and nursing staff of the National Children's Hospital casualty department, particularly Drs Joyce and Donnelly, and Miss Lynda Thompson, pulmonary function technician, for their assistance in this study.

Full size charts of normal PEFR values may be obtained from the author.

1 Worthington JR, Ahuja J. The value of pulmonary function tests in the management of acute asthma. Can Med Assoc $\mathcal{F}$ 1989 ; 140: $153-6$.

2 Carson JWK, Taylor MRH. Relapse after single dose nebulised salbutamol in children with asthma. Ir Med $\mathcal{f}$ 1985; 78: 93-6.

3 Ebden P, Carey OJ, Quinton D, Cookson JB. A study of acute asthma in the accident and emergency department. British foumal of Diseases of the Chest 1988; 82: 162-7.

4 Carson JWK, Hoey H, Taylor MRH. Growth and other factors affecting peak expiratory flow rate. Arch Dis Child 1989; 64: 96-102.

5 Le Souef PN, Geelhoed GC, Landau LI. Comparison of oximetry and peak expiratory flow in the assessment of acute childhood asthma. Aust NZ F Med 1989; 19 (5 suppl 1): 647 .

6 Charlton I, Charlton G, Broomfield J, Mullee MA Evaluation of peak flow and symptoms only management plans for control of asthma in general practice. BMF 1990; 301: 1355-9. 